\title{
Panorama e Análise de Períodos e Abordagens da Educação em Saúde no Contexto Escolar Brasileiro
}

\author{
Tiago Venturi ${ }^{1}$ \\ https://orcid.org/0000-0003-2263-8585 \\ Adriana Mohr ${ }^{2}$ \\ https://orcid.org/0000-0001-6741-2112
}

\footnotetext{
1 Universidade Federal do Paraná (UFPR) Departamento de Educação, Ensino e Ciências, Palotina, PR, Brasil.

2 Universidade Federal de Santa Catarina (UFSC) Departamento de Metodologia de Ensino, Florianópolis, SC, Brasil.
}

RESUMO:

Palavras-chave:

Este ensaio tem o objetivo de compilar um panorama de concepções, ações e tendências da Educação em Saúde no contexto escolar brasileiro, analisar e discutir suas implicações para compreender situações e desafios presentes neste campo de pesquisa e práticas. Uma revisão de literatura auxiliou a identificar duas abordagens distintas para a Educação em Saúde na escola: uma normativa e comportamentalista e outra reflexiva, voltada para a construção de conhecimentos. Essas abordagens são consequência de como a área da saúde adentrou à escola ao longo do tempo. Discutimos a importância de abordagens reflexivas e pedagógicas na Educação em Saúde para a alfabetização científica, especialmente em tempos de pandemia de Covid-19 e negacionismo científico.

\section{Panorama general y análisis de períodos y enfoques de la educación para la salud en el contexto escolar brasileño}

\section{RESUMEN:}

El objetivo de este ensayo es recopilar un panorama de concepciones, acciones y tendencias de la Educación para la Salud en el contexto escolar brasileño, analizar y discutir sus implicaciones para la comprensión de situaciones y desafíos presentes en este campo de investigación y prácticas. Una revisión de literatura ayudó a identificar dos enfoques distintos de la Promoção da Saúde; Escola; História. educación para la salud en la escuela: un enfoque normativo y conductual y uno reflexivo, dirigido a la construcción de conocimientos. Esos enfoques son una consecuencia de cómo el área de la salud ha ingresado a la escuela a lo largo del tiempo. Discutimos la importancia de los enfoques reflexivos y pedagógicos en la educación para la salud para la alfabetización científica, especialmente en tiempos de la pandemia de Covid-19 y el negacionismo científico.

Palabras clave: Promoción de la salud; Escuela; Historia. 


\section{Overview and analysis of periods and approaches to health education in the Brazilian school context}

\section{ABSTRACT:}

This essay aims to present an overview of the conceptions, actions, and trends of Health Education in the Brazilian school context, and to analyze and to discuss its implications in order to understand the challenges posed by this field and in its practice. A literature review led to the recognition two distinct approaches to Health Education at school: a normative and behavioralist and other reflective, towards the knowledge building. These approaches are a consequence from the way health education has been integrated into school along the years. We hope to contribute to stress the importance of reflective and educational approaches to Health Education for scientific literacy, especially in times of Covid-19 pandemic and scientific negationism.
Key words:

Health Promotion;

School; History.

\section{INTRODUÇÃO}

A Educação em Saúde (ES) é um campo com múltiplas percepções e compreensões acerca de seus objetivos, dos processos de ensino e aprendizagem envolvidos e do próprio conceito de saúde: são diferentes compreensões "demarcadas por distintas posições políticas e filosóficas sobre o homem e a sociedade" (Schall \& Struchiner, 1999, p.4). Neste sentido, é possível considerar a ES um campo de estudos e práticas interdisciplinares, em que se destacam as áreas da Saúde e da Educação e, especialmente, no contexto educacional, o Ensino de Ciências (EC) (Venturi, 2018).

A ES, quando desenvolvida na escola, deveria estar vinculada e ser coerente com os objetivos e metodologias próprias da instituição escolar. Considerando estes elementos, compreendemos a ES realizada na escola como um conjunto de atividades pertencentes ao currículo escolar, desenvolvidas de forma planejada e com uma intenção pedagógica, ou seja, com objetivos vinculados ao ensino e aprendizagem de algum assunto ou tema, relacionado à saúde individual e coletiva (Mohr, 2002). Quando mencionamos a coerência com objetivos escolares, queremos nos referir aos objetivos contemporâneos do EC e, neste sentido, a ênfase da ES "deveria ser no desenvolvimento da capacidade de análise, crítica e percepção das múltiplas relações sobre a natureza dos fenômenos e questões estudadas com a sociedade" (Venturi \& Mohr, 2015, p. 02).

No entanto, pesquisas como as de Mohr (2002) e de Venturi (2013) demonstraram que, apesar da ES ser desenvolvida no contexto escolar, nem sempre ela é uma atividade planejada por professores e, frequentemente, não apresenta objetivos pedagógicos alinhados com aqueles da escola contemporânea, mesmo quando desenvolvida em sala de aula e vinculada ao EC. Apesar da interdisciplinaridade e da transversalidade do tema, a ES geralmente é desenvolvida de forma disciplinar e isolada por médicos, enfermeiras e odontólogos, oriundos dos serviços de saúde. E também por pedagogos 
(Hansen, 2016), professores de Educação Física e principalmente professores de Ciências e de Biologia, geralmente licenciados em Ciências Biológicas (Venturi, 2013).

A ausência de objetivos pedagógicos legitimados pela escola atual, bem como a falta de uma perspectiva interdisciplinar, faz com que a ES na escola, via de regra, seja desenvolvida com um enfoque meramente transmissivo: informa-se estudantes sobre regras, recomendações de hábitos e normas de conduta a serem seguidas, objetivando a imediata mudança de comportamento em favor da prevenção de doenças e de uma vida dita saudável (Mohr, 2002). Tais ações, além de raramente apresentarem resultados práticos, vinculam e restringem a compreensão do conceito de saúde apenas à ausência de doenças, não permitindo um entendimento mais amplo sobre saúde individual e coletiva.

Esta maneira da ES ser comumente desenvolvida na escola, decorre do processo havido ao longo do tempo pelo qual a área da saúde adentrou o espaço escolar. Para refletir sobre outras formas possíveis de desenvolver a ES na escola - por exemplo, aquelas pautadas por perspectivas pedagógicas - tanto na prática escolar quanto na formação docente, é necessário superar uma visão normativa e limitada de ES. Para tanto, consideramos fundamental compreender aspectos epistemológicos, sua origem e construção temporal no campo educacional. Assim, este artigo tem três objetivos: compilar informações sobre a ES na escola ao longo do tempo que se encontram dispersas em distintos estudos, refletir sobre as implicações de algumas concepções e tendências teórico-práticas construídas ao longo do tempo e, assim, construir um panorama da Educação em Saúde no contexto escolar brasileiro. Ao final, tecemos considerações e estabelecemos paralelos entre o panorama apresentado e o contexto da pandemia de Covid-19, vivenciado nos últimos meses.

Caracterizamos este estudo como ensaio teórico, pois, de acordo com Meneghetti (2011), um ensaio apresenta-se como uma análise que propõe ampliação e construção de novos conhecimentos de uma forma reflexiva. Também, Severino (2000) se refere a este tipo de estudo mencionando os aspectos de exposição lógica, reflexiva, interpretativa e julgamento pessoal. Almejamos com este texto, por meio da identificação, compilação e explicitação de elementos relativos ao desenvolvimento da ES ao longo do tempo no Brasil, oportunizar reflexões conceituais, epistemológicas e sobre ações desenvolvidas neste campo de estudos e práticas de relevância, especialmente para a educação científica.

\section{SAÚDE: CONCEITO UNIVERSAL OU CONSTRUÇÃO SINGULAR NA EDUCAÇÃO EM SAÚDE?}

A concepção de saúde é um dos elementos que compõe e influencia as perspectivas e abordagens de ES no contexto escolar. A Organização Mundial da Saúde (OMS) define saúde como "um estado de completo bem-estar físico, mental e social, que não consiste apenas na ausência de doença ou de enfermidade" (OMS, 1946, p. 1). A OMS, agência subordinada à Organização das Nações Unidas, tem o objetivo de promover a saúde dos povos, defendendo princípios que colocam a saúde como um dos direitos fundamentais de todo ser humano, essencial à paz, à segurança e dependente de cooperações entre indivíduos e Estados para ser alcançada (OMS, 1946). 
A Carta de Ottawa, resultante da I Conferência Internacional sobre Promoção da Saúde ocorrida no Canadá em 1986, é um importante documento que assume a mesma definição da OMS e acrescenta que a "saúde deve ser vista como um recurso para a vida, e não como objetivo de viver. Neste sentido, a saúde é um conceito positivo, que enfatiza os recursos sociais e pessoais, bem como as capacidades físicas" (OMS, 1986). Naquele documento, ficaram estabelecidos os pré-requisitos básicos para a saúde: paz, habitação, educação, alimentação, renda, ecossistema estável, recursos sustentáveis, justiça social e equidade.

O Estado brasileiro assume a mesma definição de saúde adotada pela OMS, reforçando princípios que determinam a saúde como "direito de todos e dever do Estado, garantido mediante políticas sociais e econômicas que visem à redução do risco de doença e de outros agravos e ao acesso universal e igualitário às ações e serviços para sua promoção, proteção e recuperação" (Constituição, 1988, art. 196).

A definição oriunda da OMS é base fundamental para as políticas públicas que vêm sendo desenvolvidas em diversas áreas, especialmente na Saúde e na Educação. No entanto, definir o que é saúde não é tão fácil quanto aparentam os textos oficiais. A literatura no tema deste conceito é numerosa em diversas áreas do conhecimento. No campo do Ensino de Ciências, Martins (2017) identificou inúmeros estudos que caracterizam a definição da OMS como ultrapassada: eles ressaltam a subjetividade da construção de conceitos de saúde pelos indivíduos conforme seu contexto de vida. Isto significa dizer que compreensões como saúde, bem-estar, ou felicidade são construções do indivíduo vinculadas ao contexto social, cultural, histórico, intelectual, laboral, dentre outros, em que cada sujeito está inserido. Canguilhem (2011) faz uma crítica de caráter filosófico sobre o que pretensamente é considerado normal ou saudável e o que é patológico. Este autor afirma que para a medicina as doenças são apenas variações de fenômenos fisiológicos considerados normais, determinados por médias estatísticas. No entanto, questiona: o que é normal se considerarmos a complexidade de cada organismo individual? As médias fisiológicas podem ser aplicadas a todos os organismos humanos?

O mesmo autor afirma que, ao determinar o que é normal ou saudável e o que é patológico ou doentio, a partir de uma contabilização quantitativa, busca-se um ideal de perfeição do organismo humano. Tal ideal de perfeição iria muito além de um funcionamento equilibrado e desconsideraria as distinções individuais, entre povos, culturas e ambientes. É necessário compreender que instabilidade e irregularidade são essenciais aos processos vitais e que eles nem sempre estão adequados às métricas médicas (Canguilhem, 2011). Isto não significa diminuir ou negar a importância dos indicadores estabelecidos estatisticamente ou pela pesquisa médica. Para a elaboração de políticas públicas de saúde é imprescindível a existência de indicadores das diversas doenças e agravos à saúde, dos índices de mortalidade e dos padrões de normalidade. No entanto, diversos autores como aqueles identificados por Martins (2017), assim como Canguilhem (2011), defendem que a saúde é uma compreensão, ou uma concepção definida individualmente, que leva em conta a harmonia entre o sujeito e a sua realidade. Tratando especificamente da relação entre um pretenso normal e a ES.

A partir destas reflexões é possível compreender que tanto a saúde quanto a qualidade de vida estão intimamente interligadas e são conceitos extremamente 
complexos para serem definidos e delimitados sob bases absolutistas e arbitrárias, oriundas de normatizações estatísticas da fisiologia humana (Venturi, 2018).

Assim, uma compreensão de saúde mensurável e emergente de dados estatísticos, como aquela adotada pela OMS, pode não atender às necessidades individuais, aos elementos intrínsecos à realidade dos sujeitos e, quando adotada no contexto escolar, resultar em práticas de ES inadequadas aos objetivos de ensino e de aprendizagem. A ES no contexto escolar precisa levar em conta que não existe apenas um único conceito de saúde possível, que o conceito de saúde é amplo, polissêmico e relacionado ao contexto do sujeito. Cabe à ES desenvolver conhecimentos, autonomia e empoderamento para que cada indivíduo elabore suas próprias definições e compreensões sobre o que é saúde e o que é saudável para si e para sua comunidade (Venturi, 2018).

No entanto, como discutiremos a seguir, a ES esteve, via de regra e ao longo do tempo, atrelada a conceitos de saúde normatizadores, higienistas e, por vezes, até mesmo eugenistas, que caracterizaram sua abordagem no contexto escolar. É necessário conhecer e discutir como a saúde foi promovida ao longo do tempo e como ela adentrou o contexto escolar, para que possamos compreender como estas abordagens influenciaram e influenciam, até hoje, as compreensões e práticas de ES na escola.

\section{EDUCAÇÃO HIGIÊNICA: DOS PRIMÓRDIOS AOS TEMPOS DE COERÇÃO}

Padres jesuítas foram os precursores das práticas de saúde nos tempos do Brasil colônia (Jucá, 2008). De acordo com estudos de Antunes et al. (1999) e Jucá (2008) os jesuítas pregavam que bons hábitos de higiene, juntamente com práticas religiosas, poderiam reduzir a disseminação de moléstias entre a população. Estas ações de congregações religiosas estão muito aquém do que hoje se considera práticas de saúde, pois eram "voltadas para o alívio da alma do doente e alguns cuidados como os de higiene, de feridas; o preparo de chás, de alimentos; lavagem de roupas e do ambiente" (Antunes et al., 1999). Tais práticas perduraram por cerca de trezentos anos, sempre centradas na transmissão de informações de um pretenso sábio a um dito ignorante, propondo comportamentos e hábitos com o objetivo de evitar mortes e recuperar doentes.

Com a instalação da família real no Brasil, em 1808, ocorreram mudanças tanto no âmbito educacional (praticamente inexistente na época) quanto nas medidas de saúde implementadas (Antunes et al., 1999; Jucá, 2008). As mudanças focavam na necessidade da boa aparência física e da higiene das pessoas, que deveriam ser educadas intelectual e moralmente para poder se aproximar da nobreza (Jucá, 2008). Para tanto, as medidas de saúde e a educação formal foram destinadas às elites, objetivando a europeização dos hábitos e costumes (Silva et al., 2010). De acordo com Schall (2005), neste período as crianças, que antes eram ignoradas, passaram a ser alvo e até mesmo prisioneiras de exigências sanitaristas e higiênicas. Era um período de imposições, em que a "educação era, então, sinônimo de disciplina e domesticação" (Schall, 2005, p.43). 
Atividades visando a melhoria de condições de saúde, com objetivos de atender as classes populares, começaram a surgir somente na metade do século XIX (Wendhausen \& Saupe, 2003). Estas atividades tornaram-se, de certa forma, institucionalizadas e foram denominadas de educação higiênica. Figueiredo, Machado e Abreu (2010) afirmam que, com a expansão da cafeicultura e do comércio exterior, surgiu a necessidade de saneamento dos portos e do combate às epidemias que assolavam o país na época (febre amarela, varíola, cólera, peste bubônica, dentre outras doenças), resultando em altos índices de mortalidade da população em geral e prejuízos nas atividades econômicas do país.

Levy et al. (1997) afirmam que a educação higiênica era baseada em prescrições, ordens e medidas consideradas científicas por técnicos da área da saúde. Para impô-las, foi criada a polícia sanitária, ou polícia médica, também designada de brigada sanitária, caracterizada pelo autoritarismo e uso da força repressiva (Levy et al., 1997). Uma suposta falta de conhecimentos, informação e ignorância da classe popular era considerada como o fator causador de doenças e moléstias. Então, realizavam-se breves ações com suposto caráter de orientação visando o convencimento antes de aplicar as medidas coercitivas; afinal, as autoridades consideravam o povo incapaz de maiores entendimentos (Schall, 2005; Silva et al., 2010).

Mesmo se tivesse mais aproximações com normas e costumes vigentes à época, este modelo abusivo adotado para promover a saúde não pode sinonimizar-se ao que hoje chamamos de ações ou campanhas de saúde pública, promoção de saúde e, menos ainda, poderiam influenciar de qualquer maneira a ES realizada na escola. Tratavam-se de medidas lamentavelmente antidemocráticas e em desacordo com qualquer ideal de justiça social.

\section{EDUCAÇÃO SANITÁRIA E EDUCAÇÃO PARA A SAÚDE: TRANSMISSÃO DE SUPOSTAS VERDADES E CONVENCIMENTO}

Em fins do século XIX e início do século XX o médico e cientista Oswaldo Cruz inovou as abordagens das ações de saúde que passaram a objetivar o convencimento da população (Jucá, 2008; Silva et al., 2010). Estes últimos autores relatam que ações de saúde eram realizadas por meio de campanhas em áreas com epidemias, ainda com auxílio da força policial, quando do controle dos surtos. Estas ações visavam a adequação dos indivíduos aos padrões social e politicamente estabelecidos, justificados por uma pretensa supremacia absoluta de supostas verdades estabelecidas.

Silva et al (2010) afirmam que, em meio a uma crise sanitária, surge o médico e pesquisador Carlos Chagas: em 1923, ele cria o Departamento Nacional de Saúde vinculado ao Ministério da Justiça e lidera a primeira reforma sanitária brasileira. Segundo estes autores, nesta reforma, as medidas de saúde deixaram de ser tratadas pela polícia sanitária e passaram a ser atividades desenvolvidas por educadores sanitários. Estes, eram profissionais treinados para persuadir, convencer e conscientizar a população, especialmente crianças e trabalhadores, a adotar medidas preventivas (Silva et al., 2010). Segundo os autores, o objetivo destas medidas era evitar epidemias e prejuízos econômicos no desenvolvimento industrial latente na época. 
Silva et al. (2010) afirmam também que as ações dos educadores sanitários - mais tarde designadas de educação sanitária - tentavam afastar o caráter coercitivo da educação higiênica, adotando um caráter dito educativo, pautado pela informação e pela persuasão. Este último vinculava-se a um dogmatismo que resultou em discursos autoritários, higienistas com o foco no convencimento dos indivíduos (Rocha, 2003).

Na escola básica, a educação sanitária teve reflexos autoritários, pois foi criada a inspeção escolar, originada de concepções higienistas-eugenistas, que visava a higienização e a moralização das pessoas e das cidades (Freitas \& Martins, 2008). Santos (2011) afirma que projetos de educação higiênica, como os de Belisário Penna, que se tornaram projetos eugenistas de destaque na época, pretendiam modificar as condições que tornavam o Brasil, segundo seus defensores, um país de pobres, doentes e analfabetos.

Freitas e Martins (2008) afirmam que tal modelo se estendeu até meados da década de 1940 e tornou as escolas responsáveis pela educação sanitária. Educadores sanitários e professores atuavam no repasse de informações e no convencimento dos alunos acerca dos princípios de higiene, objetivando a correção de uma pretensa ignorância familiar (Rocha, 2003). A escola deveria eliminar atitudes viciosas, criar hábitos higiênicos e saudáveis, "[...] modelar a natureza infantil pela aquisição de hábitos que resguardassem a infância da debilidade e das moléstias" (Rocha, 2003, p.40). Portanto, "[...] as escolas seriam, além de espaço de ensino e controle social, espaços terapêuticos, recaindo sobre o professor a tarefa de transformar o mundo" (Silva et al., 2010, p.2542). Os professores do então ensino primário eram capacitados para a veiculação de informações sobre higiene e processos que envolvessem a prevenção de doenças (Silva et al., 2010).

Com o panorama até aqui esboçado, fica evidente a distância e a diferença do papel e dos objetivos gerais da escola de hoje e aqueles do passado: em épocas pretéritas talvez até fosse aceitável que a escola tivesse o objetivo de moldar pessoas e comportamentos, o que não se aceita mais atualmente, tanto no campo da pesquisa educacional, quanto no âmbito da Constituição brasileira. No entanto, se olharmos de forma mais detida e aprofundada algumas práticas de educação em saúde desenvolvidas na escola atual, damo-nos conta que ainda há nela sombras e resquícios do passado. Sustentamos que inúmeros problemas e dilemas enfrentados hoje pela ES são decorrentes de tais vestígios e da falta de crítica e de superação de fundamentos e práticas do passado. A parca presença da reflexão epistemológica e o pouco conhecimento do panorama temporal da ES na escola brasileira contribuem para que, muitas vezes, a ES seja desenvolvida de forma anacrônica, retrógrada e inadequada ao contexto escolar contemporâneo.

Por volta da década de 1930 a relação das duas áreas estreita-se ainda mais com a criação do Ministério dos Negócios da Educação e Saúde Pública. Este novo ministério vinculou educação e saúde, definindo novas políticas públicas baseando-as em medidas de controle (Lima \& Pinto, 2003).

Já na década de 1940, em meio a Segunda Guerra Mundial, foi criado o Serviço Especial de Saúde Pública (SESP), parceria entre governo brasileiro e americano. O SESP promoveu novas técnicas para prevenção de doenças, trazendo recursos audiovisuais e educação de grupos e comunidades com o objetivo de promover a saúde 
(Silva et al., 2010). Estes autores consideram que a integração e a participação comunitária nas atividades passou a ser um processo inovador no período, antes marcado por políticas centralizadoras e paternalistas. Além disso, os autores afirmam que a educação sanitária, ainda que de forma sutil, passou a levar em conta aspectos sociais e culturais.

Neste período, a escola continuou a ser um importante componente da educação sanitária. De acordo com Renovato e Bagnato (2010), inúmeros profissionais do SESP, como médicos, enfermeiros e o visitador/educador sanitário, desenvolviam atividades sanitárias e educativas no contexto escolar e nas comunidades do seu entorno. $\mathrm{O}$ reconhecimento do indivíduo inserido em uma comunidade, de interações e de condições sociais que interferem diretamente no campo da saúde, trouxe novos elementos que foram incorporados às ações educativas realizadas na década seguinte. A partir dos anos 1950 houve mudança na designação das atividades educativas que passaram a ser denominadas Educação para a Saúde. As medidas adotadas na educação para saúde pautavam-se "por uma ideologia modernizadora que tinha por meta remover os obstáculos culturais e psicossociais às inovações tecnológicas de controle de doenças" (Silva et al., 2010, p.2544).

No entanto, Freitas e Martins (2008, p.13) afirmam que este formato fora baseado em um modelo fortemente biomédico, com visão reducionista e centrada em aspectos anátomo-fisiológicos dos processos saúde-doença, onde "A saúde é vista como uma questão relativa ao organismo, seus aspectos psicológicos, sociais e ambientais não são levados em conta". Silva et al. (2010) afirmam que os interesses políticos e econômicos das elites dominavam as ações de saúde realizadas na época, motivo pelo qual, a educação para a saúde voltava-se para a imposição de normas e comportamentos considerados adequados pelos detentores do poder.

Desta forma, Venturi (2013) observa que, apesar de um discurso modernizador, continuava-se praticando ações que objetivavam a redução de doenças, com foco no indivíduo, típicas do antigo modelo da educação higiênica. Mudanças neste paradigma começaram a ser observados apenas nos anos seguintes, conforme discutiremos a seguir.

\section{HORTÊNSIA HURPIA DE HOLLANDA: NOVAS SIGNIFICAÇÕES DE EDUCAÇÃO E DE SAÚDE PARA A EDUCAÇÃO EM SAÚDE}

Diversos profissionais da área da saúde e da educação passaram a desenvolver atividades de forma conjunta a partir de meados de 1960: surgiram então as chamadas equipes multiprofissionais. Neste período, as atividades educativas que tratavam de temas de saúde passaram a ser denominadas de Educação em Saúde (ES). Apesar da alteração da designação, as atividades permaneceram focadas na mudança de comportamento, em medidas prescritivas e preventivas, como as adotadas em décadas anteriores (Silva et al., 2010). Gazzinelli et al. (2005) afirmam que tais ações comportamentalistas e ultrapassadas tratavam o público alvo como objeto a ser modificado, ignorando a necessidade de transformações das situações de desigualdade sociais que envolvem renda, saneamento básico, acesso à educação e à saúde. 
Portanto, é importante esclarecer que, apesar de possuírem o mesmo nome Educação em Saúde - as ações realizadas naquele momento não apresentavam características pedagógicas hoje reivindicadas e defendidas para a ES: construção de conhecimentos relacionados à saúde, autonomia de pensamento e desenvolvimento de senso crítico.

No entanto, surge neste período uma nova e importante figura. A educadora Hortênsia Hurpia de Hollanda foi precursora de novas políticas, práticas e abordagens educativas no campo da ES (Schall, 1999). Esta autora afirma que Hortênsia ampliou verdadeiramente a compreensão de saúde, para além de aspectos individuais e fisiológicos, dando real importância aos fatores comunitários, sociais e ambientais. Além disso, a valorização da participação comunitária nas ações de saúde, permitiu, segundo Schall (1999), um trabalho inovador e pioneiro para a época que pode, ainda assim, ser considerado na atualidade.

A carreira de Hortênsia de Hollanda foi marcada por sua atuação como docente, consultora da OMS e educadora responsável pela Divisão Nacional de Educação Sanitária do Ministério da Saúde, órgão responsável pelas atividades de ES na época (Schall, 1999). À frente desta instituição, Hollanda liderou uma equipe, formada por pesquisadores, professores e membros da comunidade, a fim de desenvolver materiais para ES, resultando no livro "Saúde como Compreensão de Vida" (Diniz et al., 2009). A obra foi utilizada para o desenvolvimento da ES em escolas e, por ter sido produzida em meio escolar, com a participação de membros da comunidade, possuía uma abordagem conectada e contextualizada à vivência dos alunos e relacionada à realidade da comunidade (Diniz et al., 2009). Por isto, estas autoras a julgam uma obra avançada para o seu tempo. Hollanda considerava que a ES deve "estruturar um mínimo de conhecimentos e atitudes capazes de levar o indivíduo à compreensão dos problemas de saúde, estimulando sua autonomia e responsabilidade, associadas a uma ação coletiva" (Diniz et al., 2009, p.122).

Como afirma Schall (1999), tratava-se de uma abordagem humanista e humanitária, em que a ES utilizava-se de metodologias que oportunizavam momentos de conversas e na qual a prioridade era ouvir as pessoas, compreender suas demandas e realidade. Schall (1999) ainda observa que, em um período em que os profissionais da saúde eram considerados os detentores de um conhecimento científico a ser transmitido de forma mecânica e vertical, uma ES que partia daquilo que as pessoas já sabiam e vivenciavam, era, no mínimo, uma atividade educativa desafiadora. Com efeito, para Hollanda, era importante desenvolver trabalhos contextualizados, que integrassem a cultura da comunidade e dos indivíduos.

Hollanda considerava o ambiente como fator condicionante de saúde. Mas ao tratar de ambiente, referia-se às relações existentes em níveis biológicos, sociais, econômicos, condições de habitação, juntamente com as relações existentes entre comunidade e profissionais da saúde (Schall, 1999). O simples repasse de informações pelos profissionais de saúde não resulta em mudança de comportamento da comunidade. Diniz et al. (2009, p. 540) analisando as concepções de Hollanda para intervenções na área da saúde afirmam que para esta última,

[...] é preciso desenvolver um processo de compreensão da importância das mudanças culturais e ambientais, visando preservar determinado nível de saúde ou alterá-lo. Só compactuam e participam das mudanças as comunidades que se sentem efetivamente sensibilizadas. Deve haver, 
portanto, adesão decorrente de reflexão, entendimento, aceitação e incorporação; jamais uma imposição via decretos ou ordens do mundo da ciência e do poder político.

Uma forma de estabelecer relações e vínculos entre profissionais da saúde e comunidade era por meio da interação entre escolas, comunidades e serviços de saúde. Em entrevista a Schall (1999, p. 153), Hollanda afirmou que "[...] se a escola não tem um entrosamento com a comunidade e com os serviços de saúde, muitas coisas vão se chocar no caminho". A busca por interação com a comunidade era fundamental para compreender as raízes das mazelas e para procurar formas de resolver os problemas de forma coletiva. O trabalho de Hollanda é avançado, inovador e libertador, pois em uma época em que se objetivava mudanças de comportamento de forma normativa, ele visava o conhecimento como condutor das mudanças. Seguramente, os princípios e ações de Hortênsia Hurpia de Hollanda representam grandes contribuições para a ES e para a saúde pública no Brasil da década de 1960 e 1970. No entanto, infelizmente, muito pouco, ou quase nada de seu legado chegou ao contexto escolar, como discutiremos no próximo item. Se suas contribuições tivessem se transformado em políticas públicas educacionais, talvez muito da ES da atualidade já se tivesse desvinculado de formatos normativos e comportamentalistas tão retrógrados e anacrônicos.

\section{EDUCAÇÃO EM SAÚDE NA ESCOLA: DOS PROGRAMAS DE SAÚDE À BASE NACIONAL COMUM CURRICULAR}

Já discutimos que a partir dos anos de 1970 o campo da saúde pública superou a ênfase única no indivíduo e passou a considerar aspectos sociais, comunitários e ambientais. Wedhausen e Saupe (2003) afirmam que, neste período, população e profissionais da saúde compartilhavam conhecimentos em busca de uma vida mais saudável e formavam movimentos que lutavam por uma reforma sanitária democrática (Wendhausen \& Saupe, 2003).

Também nessa década, por intermédio da Lei 5.692 de 1971, a educação escolar recebeu a inserção de Programas de Saúde na escola: “Art. $7^{\circ}$ Será obrigatória a inclusão de Educação Moral e Cívica, Educação Física, Educação Artística e Programas de Saúde nos currículos plenos dos estabelecimentos de $1^{\circ}$ e $2^{\circ}$ graus, observado quanto à primeira o disposto no Decreto-Lei n ${ }^{\circ}$ 869, de 12 de setembro de 1969" (Lei n. 5.692, 1971, p. 04). Lemônaco (2004) afirma que o maior objetivo dos Programas de Saúde na escola era a promoção de comportamentos adequados para a saúde e sua manutenção. Também, que a legislação previa acesso a noções de higiene, preservação da saúde e puericultura.

A regulamentação e especificação dos Programas de Saúde na escola deu-se em 1974, com a aprovação do Parecer 2.264/74 pelo Conselho Federal de Educação (Mohr, 2002). A partir deste momento a ES tornou-se uma atividade curricular formal integrante do sistema educacional brasileiro. De acordo com Bagnato (1990), atividades antes vinculadas à inspeção e normatização de condutas higiênicas, passam a ter como objetivo a formação de hábitos e atitudes, através de estratégias consideradas pedagógicas e que tinham abrangência intra e extraescolar. Segundo a autora, as responsabilidades da escola foram ampliadas e o parecer atribuía à escola o 
oferecimento de oportunidades para o desenvolvimento do aluno e de sua saúde. No entanto, o referido parecer não previa ou orientava o formato de estruturação do currículo escolar para o cumprimento das exigências legais. Assim, via de regra, as escolas vincularam os Programas de Saúde à disciplina de Ciências ou passaram a desenvolvê-los através de disciplina específica denominada Programas de Saúde (a cargo do professor de Ciências) ou de atividade intitulada Práticas de Saúde (ou Projetos de Saúde Escolar), realizada por técnicos de saúde (Lemônaco, 2004). Compreendemos este momento como a origem do vínculo, até hoje existente, entre a ES e as disciplinas de Ciências e de Biologia, ministradas por licenciados em Ciências Biológicas.

É importante ressaltar as articulações intersetoriais entre escolas, comunidades, serviços de saúde e universidades locais que eram encorajadas no parecer:

É recomendável, portanto, e sempre que possível, que antes da execução dos programas de saúde haja a formação de grupos de trabalho constituídos por representantes dos órgãos de saúde, do pessoal docente de $1^{\circ}$ e $2^{\circ}$ graus e das universidades locais. Esses elementos deverão planejar os programas de saúde buscando compatibilizá-los com as necessidades do meio, do aluno e com os recursos existentes para a elaboração do material adequado, sempre sem perder de vista a integração da escola nos movimentos de mobilização comunitária, visando sua adequação aos objetivos propostos e à melhoria do meio ambiente. (Conselho Federal de Educação, 1974, p.65).

Bagnato (1990) afirma que o incentivo a essa articulação, tinha como objetivo integrar os Programas de Saúde às demandas das comunidades locais, por meio de uma abordagem biopsicossocial. Orientação, esta, bastante semelhante à visão proposta por Hortênsia de Hollanda, como vimos na seção anterior. Contudo, na prática, infelizmente, esta articulação pouco se desenvolveu (Mohr, 2002).

Neste texto, anteriormente notamos o surgimento de um movimento em prol da saúde coletiva e de um enfoque comunitário e ambiental que leva em conta outros aspectos e condicionantes da saúde. Também, já afirmamos que este enfoque, via de regra, não resultou em reformulação de práticas no contexto escolar. Schall (2005, p. 42) afirma que na década de 1980, a ES escolar, mesmo nos Programas de Saúde, ainda "caracterizava-se, principalmente, por imposição de hábitos e transmissão de conhecimentos, focalizados, sobretudo nas relações de causa e efeitos biológicos, numa visão positivista da saúde e das relações ambientais, desconsiderando os aspectos sóciohistórico-culturais" e que a ênfase na transmissão de conteúdos e informações era o mesmo do Ensino de Ciências desenvolvido na época. Assim, como já afirmamos em outro estudo, ao longo destas várias décadas não houve uma ruptura entre as formas de compreender a ES:

As características destes períodos podem ser verificadas atualmente, pois as mudanças ocorridas nas formas de tratar as atividades de ES não se caracterizavam como um encerramento de período ou ciclo, mas sim como uma sobreposição de períodos, onde as atividades educativas em saúde agregavam as características dos períodos anteriores (Venturi, 2013, p.39)

Em meados da década de 1980, surgiram os princípios e o conceito de Promoção da Saúde, propostos pela OMS a partir da Conferência de Ottawa em 1986 e vigentes até hoje. Ao lado da consideração das pessoas, suas concepções, sua realidade, sua comunidade e sua participação de forma dinâmica em todo o processo em favor da saúde, a educação escolar passou a ser primordial à promoção da saúde (OMS, 1986). Esta concepção foi reafirmada posteriormente pela declaração de Sundsvall (MS, 2002) e pelo Documento de Nairobi (OMS, 2009). 
No Brasil, na década de 1990, foram promulgados documentos educacionais pósredemocratização. Em 1996 a Lei de Diretrizes e Bases da Educação Nacional (LDBEN) determinou, em seu artigo primeiro, que "a educação abrange os processos formativos que se desenvolvem na vida familiar, na convivência humana, no trabalho, nas instituições de ensino e pesquisa, nos movimentos sociais e organizações da sociedade civil e nas manifestações culturais" (Lei n. 9.394, 1996). Nesta legislação não há menção específica ou explícita à ES; contudo, seu art. $4^{\circ}$ - inciso VIII, determina o "atendimento ao educando, no ensino fundamental público, por meio de programas suplementares de material didático-escolar, transporte, alimentação e assistência à saúde" (Lei n. 9.394, 1996). Venturi (2013) afirma que essa assistência à saúde pode ser observada por meio da inserção de ações pontuais na educação básica, tais como o combate a parasitas, consultas oftalmológicas, controle nutricional e promoção de saúde bucal, não sendo, via de regra, atividades integradas ao currículo escolar e às atividades docentes.

No período que se seguiu à promulgação da LDBEN, novos documentos surgiram para regulamentar e orientar a condução da educação brasileira. As Diretrizes Curriculares Nacionais (DCN) tiveram o objetivo de estabelecer, entre outros aspectos, os conhecimentos mínimos necessários à formação escolar do indivíduo para o exercício da cidadania. Para tanto, o documento conceituou vida cidadã como o "exercício de direitos e deveres de pessoas, grupos e instituições na sociedade que, em sinergia, em movimento cheio de energias que se trocam e se articulam, influem sobre múltiplos aspectos, podendo, assim, viver bem e transformar a convivência para melhor" (MEC, 1998a, p. 9). Saúde, sexualidade, vida familiar e social, meio ambiente, trabalho, ciência, tecnologia, cultura e linguagens, são temas que, articulados com os conteúdos disciplinares, tornaram-se imprescindíveis à educação básica e à formação cidadã. Tal articulação deu-se com a implementação dos Parâmetros Curriculares Nacionais (PCN), que instituíram seis temas transversais, dentre eles o tema saúde (MEC, 1997, 1998b).

Jucá (2008), ao analisar as concepções de ES presente nos PCN, afirma que ali se mantém objetivos e compreensões semelhantes àquelas previstas pelos antigos Programas de Saúde da década de 1970, frustrando as tentativas de dissociação da ES de uma perspectiva sanitária e higienista. Concordamos com o diagnóstico da autora ao mesmo tempo que notamos, além do nome já ultrapassado - educação para a saúde que o documento avança quanto à compreensão ampliada de saúde:

O que se entende por saúde depende da visão que se tenha do ser humano e de sua relação com o ambiente, e este entendimento pode variar de um indivíduo para outro, de uma cultura para outra e ao longo do tempo. A diversidade de expressões idiomáticas e artísticas relacionadas ao assunto pode ilustrar a enorme variedade de maneiras de sentir, viver e explicitar valores e padrões de saúde ou doença. É necessário reconhecer que a compreensão de saúde tem alto grau de subjetividade e determinação histórica, na medida em que indivíduos e coletividades consideram ter mais ou menos saúde dependendo do momento, do referencial e dos valores que atribuam a uma situação (MEC, 1997, p. 250).

Destacamos ainda, um dos objetivos relacionados ao tema saúde nos PCN: "Espera-se, portanto, que ao final do ensino fundamental os alunos sejam capazes de: compreender saúde como direito de cidadania, valorizando as ações voltadas para sua promoção, proteção e recuperação [...]" (MEC, 1997, p. 269). No excerto, é possível observar a promoção da saúde como um dos objetivos presentes no documento. Esta é considerada consequência direta da educação em saúde, "da adoção de estilos de vida 
saudáveis, do desenvolvimento de aptidões e capacidades individuais, da produção de um ambiente saudável” (MEC, 1997, p. 255). Para tanto, o documento prevê que o ensino e a aprendizagem de conceitos na escola devam subsidiar "a utilização de medidas práticas de promoção, proteção e recuperação da saúde" (MEC, 1997, p. 269). Fica evidente que a aquisição de hábitos e atitudes saudáveis são os objetivos mais importantes da ES segundo os PCN e que aí se mantém uma forte ligação da ES com aspectos biológicos, sanitários e com a higiene do corpo (Venturi, 2013). Por isto, já afirmamos em outros estudos (Mohr, 2009, Venturi, 2013) que o documento dos PCN é repleto de orientações normativas e prescritivas, que, via de regra, desconsideram o contexto cultural, social e familiar do aluno.

Outro aspecto importante notado pelos estudos de Mohr (2009), Jucá (2008) e Venturi (2013), é que os PCN vinculam fortemente ES à disciplina de Ciências, enfraquecendo e até mesmo abdicando da transversalidade inicialmente proposta. Mohr (2002) considera que esta vinculação é consequência da perspectiva biomédica adotada pela ES quando centrada no estudo de aspectos anatômicos e fisiológicos dos processos de saúde-doença e do desenvolvimento humano, além de, muitas vezes, o tema constar somente nos livros didáticos das disciplinas de Ciências e de Biologia.

Investigações detalhadas dos PCN de Ciências Naturais, como as realizadas por Jucá (2008) e Venturi (2013), concluíram que a ES assume diferentes perspectivas de acordo com os níveis educacionais: no primeiro e no segundo ciclo do ensino fundamental objetiva-se o desenvolvimento de hábitos que podem influenciar na sanidade dos indivíduos e se explora, de forma inicial, os fatores ambientais e agentes etiológicos, que devem ser aprofundados nos ciclos seguintes (Jucá, 2008). No terceiro e no quarto ciclo, os objetivos e conteúdos estão centrados nas compreensões das relações entre corpo, ambiente, sociedade e cultura para a aquisição de hábitos saudáveis:

Os conteúdos indicados para os trabalhos nos terceiro e quarto ciclos, enfatizam a anatomia e a fisiologia do corpo humano, bem como a retomada da necessidade de falar de doença para trabalhar ES. Mesmo apresentando inovações, os PCNs continuam apegados aos antigos Programas de Saúde, demonstrando que antigas e antiquadas maneiras de compreender ES ainda não foram superadas (Venturi, 2013, p.46).

Apesar das críticas ao documento, Monteiro e Bizzo (2015, p. 423) ressaltam a necessidade de destacar os avanços, tanto do ponto de vista conceitual, quanto epistemológico e político nas orientações expressas nos PCN, ao "afirmar a saúde como direito e determinada por fatores que dizem respeito à construção de condições de vida minimamente dignas".

Análises semelhantes foram realizadas por Sousa, Guimarães e Amantes (2019) nos PCN para o Ensino Médio, publicados no final da década, em 1999: as orientações para esta etapa, tanto nos documentos gerais quanto nos textos da área de Ciências da Natureza, associam degradação ambiental e agravos à saúde. Contudo, segundo estes autores, os documentos mencionam apenas o envolvimento da disciplina de Biologia ao tema. Os autores ainda observaram a inexistência de orientações acerca da interdisciplinaridade e que, no Ensino Médio, reforça-se um modelo biomédico de saúde, tal qual observado na análise dos PCN do Ensino Fundamental. 
Os autores acima mencionados ainda afirmam que nos PCN+ (que complementam as orientações curriculares, em 2002) foi "reforçado o entendimento da saúde associada aos cuidados com o corpo, ao funcionamento dos órgãos e dos sistemas e atrelada às diversas doenças". Tal documento também indica apenas a Biologia no desenvolvimento do tema saúde na escola, mas aponta a necessidade de relacionar saúde com as condições de vida da população, as desigualdades e os contrastes regionais (Sousa, Guimarães \& Amantes, 2019). Os autores afirmam que os PCN+ lançaram um olhar social para a saúde, embora a ênfase em aspectos anátomo-fisiológicos do corpo humano tenha permanecido.

Em 2006 foram publicadas novas Orientações Curriculares para o Ensino Médio (OCEM) e em 2013, Diretrizes Curriculares Nacionais da Educação Básica (DCNEB). As OCEM (MEC, 2006) fazem apenas uma breve menção que a Biologia deve abordar assuntos relacionados à saúde, ao corpo humano, à adolescência e à sexualidade. Já as DCNEB (MEC, 2013) se referem à saúde apenas como um campo de conhecimentos e serviços. O documento assume, assim, para a escola, uma perspectiva assistencialista que é associada a outros direitos fundamentais e constitucionais. Estas referências superficiais à saúde e à ES demonstram o silêncio destes documentos quanto ao tema, ao mesmo tempo que reforçam as perspectivas presentes nos demais e anteriores documentos curriculares.

Os estudos dos documentos curriculares mencionados demonstram que neles, conteúdos e perspectivas de ES retornam ou permanecem enraizadas àquelas do passado brasileiro, apresentando características das atividades realizadas nas décadas de 1960 e 1970. Isto é uma lástima, pois, para além dos conteúdos, a proposta de transversalidade para ES poderia favorecer abordagens interdisciplinares importantes aos processos de ensino e de aprendizagem. Contudo, os documentos não apresentam indicações metodológicas interdisciplinares consistentes, incorrendo em falta de orientação e suporte teórico-metodológico ao professor. Além disso, a formação para tal desenvolvimento foi praticamente inexistente (Mohr, 2002; Jucá, 2008). Concordamos que

proposições curriculares inovadoras como os PCN exigem, para sua consecução, novos procedimentos didáticos, e estes não surgem através de uma simples recomendação escrita: são necessários professores preparados e dispostos a criá-los e utilizá-los. Quando se pensa em falta de formação inicial e continuada as quais está submetido grande parte dos professores no Brasil, este aspecto assume contornos dramáticos. Novas orientações curriculares devem ser, pois, pensadas em estreita ligação com a formação (inicial e continuada) dos professores que darão vida (ou não) a elas nas escolas (Mohr, 2009, p. 124)

Apesar das críticas externadas, reconhecemos os PCN como documentos que avançam ao afirmar a importância da ES no contexto escolar e por trazer uma tentativa de ampliar e modernizar a concepção de saúde. No entanto, os PCN não tiveram a oportunidade de ser revisitados, nem teórica, nem metodologicamente, muito menos de ser aprimorados para uma efetiva implementação da transversalidade do tema da saúde no contexto escolar. Os PCN foram revogados pela Resolução do Conselho Nacional de Educação - CNE/CP n 2/2017 que instituiu a Base Nacional Comum Curricular (BNCC).

Segundo seu próprio texto, a BNCC resulta de esforços políticos e tem por justificativa oportunizar aos alunos uma base única e comum de aprendizagem em todo território nacional, bem como o desenvolvimento de competências e habilidades 
consideradas fundamentais para a formação dos cidadãos (MEC, 2017). Mas, diferentemente do que é afirmado no documento, a BNCC traz enormes prejuízos e retrocessos à educação nacional, além de desastroso e impositivo processo na forma de elaboração e implantação no contexto escolar. Concordamos com Cássio (2018, p. 240) que considera a BNCC uma política de centralização e de obrigatoriedade curricular nacional, que implicará diretamente em "políticas estatais de compra e distribuição de materiais didáticos e de formação inicial e continuada de professores, além de influir nas (e de ser influenciada por) avaliações em larga escala".

No que se refere à ES, constatamos que o documento (MEC, 2018) não menciona a expressão. No entanto, é possível identificar 60 menções à palavra saúde, via de regra, associada ao termo 'cuidados em saúde', principalmente nas habilidades a serem desenvolvidas pelo componente curricular Ciências, do Ensino Fundamental. Para este, o documento determina que sejam abordadas três unidades temáticas, "Matéria e Energia", "Vida e Evolução" e "Terra e Universo" de forma integrada, onde essa integração

[...] se evidencia quando temas importantes como a sustentabilidade socioambiental, o ambiente, a saúde e a tecnologia são desenvolvidos nas três unidades temáticas. Por exemplo, para que o estudante compreenda saúde de forma abrangente, e não relacionada apenas ao seu próprio corpo, é necessário que ele seja estimulado a pensar em saneamento básico, geração de energia, impactos ambientais, além da ideia de que medicamentos são substâncias sintéticas que atuam no funcionamento do organismo (MEC, 2017, p.329, grifos nossos).

Na BNCC há um aparente discurso para ampliar a visão de saúde para além de aspectos anátomo-fisiológicos e da ausência de doença, retomando discussões sociais e ambientais. Contudo, quando analisamos as competências específicas a serem desenvolvidas, observamos que o documento recomenda que o ensino proporcione momentos para que os indivíduos possam "vivenciar práticas corporais e significá-las em seu projeto de vida, como forma de autoconhecimento, autocuidado com o corpo e com a saúde, socialização e entretenimento" (MEC, 2017, p. 245). O que claramente nos parece uma visão reducionista da saúde, voltada apenas ao cuidado e que responsabiliza unicamente o indivíduo por sua saúde.

Sousa, Guimarães e Amantes (2019) afirmam que, em um documento que se propõe como basilar à estruturação dos currículos, a saúde é um tema pouco explorado, apresentando apenas uma abordagem genérica, superficial e repleta de contradições em sua concepção. Além disso, ali não existem indicativos teóricos ou metodológicos para abordar o tema da saúde. Consideramos a BNCC um documento repleto de retrocessos, inclusive se o compararmos aos PCN os quais, mesmo que de forma insuficiente, mencionavam a ES, sua importância e complexidade como tema curricular.

A análise de documentos curriculares e educacionais governamentais das últimas décadas é fundamental para que possamos compreender o panorama passado e presente da ES na escola brasileira. Mohr (2002) e Carvalho (2012) discutem que os currículos prescritos podem não ser determinantes na ES, mas essas políticas educacionais exercem grandes influências sobre as práticas pedagógicas nos contextos educacionais, principalmente se considerarmos programas de distribuição de livros didáticos e de avaliações em larga escala.

Os apontamentos compilados no presente estudo sobre ações, objetivos, metodologias e conteúdos desenvolvidos pela ES na escola ao longo do tempo nos 
permitem afirmar que ainda não avançamos suficientemente em uma ES que supere abordagens normativas e comportamentalistas, tanto no que diz respeito às políticas públicas educacionais quanto nas práticas escolares. Infelizmente e para além disto, agora, de forma anacrônica e insensata, a BNCC faz com que retrocedamos 50 anos (à era pré LDB de 1971), ao, entre outros aspectos a deplorar, retirar a ES do currículo escolar.

\section{PERÍODOS E ABORDAGENS DA EDUCAÇÃO EM SAÚDE NA ESCOLA BRASILEIRA}

Neste texto discutimos que a ES desenvolvida na escola é resultado de uma imbricada relação entre duas grandes áreas de pesquisa e de prática: a educação e a saúde. Verificamos que, ao longo de diversas épocas, as atividades que relacionam saúde e educação já foram designadas por distintas expressões: educação higiênica, educação sanitária, educação para a saúde, educação em saúde. Também, que estas atividades possuem distintas e características abordagens, objetivos, conteúdos e metodologias, tanto em contexto escolar quanto fora da escola e, por isso, resultam em distintas ações.

A polissemia de expressões que a designam é sintoma dos diferentes tempos apresentados anteriormente. Julgamos que não há delimitação temporal absoluta entre eles; tampouco identificamos rupturas bruscas na forma de compreender e empreender a abordagem do tema da saúde como parte da atividade da escola nos diferentes tempos (Venturi, 2018). Contudo, acreditamos que é possível identificar cinco períodos que sumarizamos a seguir:

Primórdios do Tema Saúde na Escola: período que vai desde a era colonial até por volta da década de 1950. É marcado por objetivos higienistas, comportamentalistas e preventivos, quando se destaca a puericultura no contexto escolar.

Transição e Pioneirismo: período que abrange desde a década de 1950, quando surgem novas tecnologias educativas propostas pela Fundação de Serviço de Especial de Saúde Pública (SESP), até os trabalhos desenvolvidos por Hortênsia Hurpia de Hollanda entre 1960 e 1970. Período no qual temas de saúde continuam sendo desenvolvidos na escola almejando mudança de comportamento, mas se amplia a compreensão de saúde envolvida e passa-se a considerar aspectos coletivos e ambientais nas ações.

Formalização no Currículo Escolar: período no qual surgem os Programas de Saúde, institucionalizados pela Lei de Diretrizes e Bases da Educação de 1971 e regulamentados pelo Parecer 2.264/74. As escolas geralmente vincularam os Programas de Saúde à disciplina de Ciências e de Biologia, mantendo atividades e objetivos com características preventivas, higienistas e comportamentalistas.

Transversalidade Curricular: período em que surgem a LDBEN de 1996, as DCN e os PCN, que incluem saúde como um dos Temas Transversais a serem desenvolvidos na escola. Os PCN mostram avanços ao propor um ensino interdisciplinar do tema, levando em conta aspectos sociais e ambientais; contudo seus objetivos permanecem semelhantes àqueles verificados nos períodos anteriores. 
Silenciamento Curricular: momento atual com a revogação dos PCN e publicação da BNCC, que silencia acerca da ES. Nas poucas menções à saúde, retorna ao ensino dos processos saúde-doença, conteúdos anátomo-fisiológicos e recomendações de comportamentos considerados adequados e saudáveis e prega o desenvolvimento de competências para o autocuidado.

Ao estabelecer estes períodos temporais apontamos também as distintas concepções, ou abordagens de saúde associadas às políticas públicas de saúde e de educação vigentes em cada um. Estas últimas estabelecem vínculos especialmente com as abordagens higienista, biomédica e comportamental. A abordagem higienista tem seu foco na higiene corporal para a prevenção de doenças, desconsidera fatores socioculturais e econômicos do processo de promoção da saúde (Carvalho, 2012); a abordagem biomédica fundamenta-se no binômio saúde-doença no qual a saúde é vista como ausência de doença, caracteriza-se por uma perspectiva funcionalista (saúde e doença são resultados da (a)normalidade do funcionamento dos órgãos de cada indivíduo), e considera apenas aspectos anatômicos, fisiológicos e bioquímicos, negligenciando outros aspectos que influenciam a saúde (Martins et al., 2015). Por fim, a abordagem comportamental, considera fundamental a mudança de comportamento do indivíduo, o que se alcançaria com orientações acerca de condutas saudáveis, higiênicas e preventivas, associada especialmente à abordagem biomédica (Schall, 1996; Martins et al., 2015).

A interação, desenvolvimento e sedimentação destas abordagens ao longo do tempo resultaram, no presente, em uma ES no contexto escolar que caracterizamos como normativa, vinculadas a objetivos de mudança instantânea de comportamentos, o que condena o ensino à postura de ditar condutas para prevenção de doenças e agravos. A prática escolar nesta abordagem de ES, geralmente utilizou-se e utiliza-se de estratégias diretivas, instrutivas e tecnicistas. Mesmo nas raras vezes em que tenta adotar a dimensão social e ambiental para ES, suas práticas visam a adoção de atitudes, comportamentos e hábitos considerados saudáveis por quem impõe a atividade (Venturi, 2018).

\section{ALGUMAS CONSIDERAÇÕES E REFLEXÕES EM TEMPOS DE PANDEMIA}

Desde o primeiro semestre de 2020, o mundo encontra-se paralisado em meio a um caos sanitário, antes dificilmente imaginável, ocasionado por um coronavírus. Em 11 de março de 2020 a OMS decretou situação de pandemia mundial em decorrência da disseminação da Covid-19, doença causada pelo vírus Sars-Cov-2 (OMS, 2020a). Vivenciamos quarentena global, momentos de apreensão, medos e preocupações, em que hospitais ficam lotados rapidamente, milhares de vidas são ceifadas diariamente, enquanto aguardamos avanços científicos que permitam o surgimento de vacinas ou de medicação paliativa eficaz.

Uma vez que a ciência ainda não identificou alternativas efetivas para o tratamento e prevenção da doença, afastamento e isolamento social são as únicas alternativas para poupar vidas. Paralela e contraditoriamente a estas evidências, vivenciamos disseminação de notícias falsas - propagadas também por agentes com importantes cargos públicos - que relatam supostas curas milagrosas, ou que propõem 
a ministração de drogas sem comprovação científica de sua eficácia. Vemos, também, recomendações de retomada das atividades econômicas habituais e o fim do isolamento, atitudes que menosprezam a mortalidade da doença, além de outras assustadoras ações que não possuem respaldo científico.

A OMS (2020b) declarou que, além de lidarmos com uma pandemia, o mundo precisa lidar com uma "infodemia", ou seja, boatos repletos de desinformação acerca da Covid-19 que prejudicam ações de prevenção, controle e tratamento da doença. Então nos perguntamos: e a ES neste contexto? Se e quais relações podemos estabelecer entre a infodemia e a ES?

Obviamente não há respostas prontas ou simples a estas questões. Contudo pensamos que refletir sobre elas nos permitem avançar na análise e na crítica do desenvolvimento da ES, especialmente na escola. Mais: defendemos o desenvolvimento de uma ES em moldes mais contemporâneos, ou seja, aqueles que ultrapassem o caráter normativo e prescritivo que vimos descrevendo, e que contribua para a autonomia e aumento da capacidade de crítica do estudante. Pensamos que a ES pode ser mais do que tratar de temas de saúde:

Desta forma, a educação ambiental e a educação em saúde assumem um caráter muito mais amplo do que a mera (mas importante e indispensável) aquisição de conhecimentos, passando a ser um momento de reflexão e questionamento das condições de vida, suas causas e consequências, e se tornando um instrumento para a construção e consolidação da cidadania (Mohr \& Schall, 1992, p. 202).

Certamente tal meta não é simples ou fácil de ser alcançada. Algumas considerações e sugestões para outros caminhos podem ser encontradas em trabalhos anteriores que tratam da natureza e objetivos da ES na escola (Mohr, 2002), da metodologia e da formação de professores (Venturi, 2018).

Tentando gerar elementos para reflexão a partir da indagação anteriormente proposta, fazemos as considerações que seguem.

A forma como a ES vem sendo compreendida e desenvolvida no contexto escolar, associada a um EC que, quando trata do tema, é conteudista e acrítica, não contribui para a construção de conhecimentos científicos, para compreensão e confiança nos conhecimentos produzidos pela ciência, de forma geral e no campo da saúde de forma específica, nem colabora com a educação científica dos estudantes. Tal quadro contribui para o que verificamos atualmente: abordagens conservadoras, antiquadas e sombrias tomam força e colocam milhares de vidas em risco.

Da mesma forma, parece-nos que a ES, nos moldes e objetivos com os quais vem sendo realizada na escola, parece não contribuir para evitar a infodemia. E abordagens e concepções de saúde desconectadas do conhecimento científico, porém, normativas e dogmáticas, ressurgiram. No contexto da pandemia, mas não só, verificamos um grande contingente de pessoas que, quanto aos processos saúde-doença, preferem confiar no que Martins et al. (2015) designam por "abordagens religiosas": relacionadas a aspectos sobrenaturais como magia, curandeirismo e fé, onde as religiões são os pilares destas abordagens de saúde. Ou pensam e agem conforme suas próprias crenças individuais, emoções, preconceitos, necessidades econômicas, dentre outros fatores que optam por negar a ciência. Assim, evidências, conhecimentos e empreendimentos científicos para a saúde e a autonomia de cada um frente ao conhecimento para a tomada de decisão - 
vitais, não só em meio a uma pandemia, mas ao longo das nossas vidas - são preteridos nos debates sociais e políticos.

Para desenvolver autonomia e uma postura informada e crítica que inclua o campo científico como parte do conjunto de conhecimentos disponíveis aos indivíduos, defendemos uma ES que, mais do que normas e atitudes, seja, antes de tudo e - como seu nome propõe - uma EDUCAÇÃO que toma temas de saúde como objeto de estudo. E como em qualquer processo educacional que mereça este nome, é a construção crítica do CONHECIMENTO que tem papel central. Os objetivos de uma ES reflexiva precisam estar centrados em adquirir e desenvolver conhecimentos, incentivar debates e o pensamento crítico. Uma eventual mudança de comportamento do indivíduo pode ser consequência indireta da aprendizagem. Além das dimensões sociais e ambientais, nesta abordagem de ES leva-se em conta outros aspectos como os culturais, psicológicos, emocionais e cognitivos (Venturi, 2018). A ES reflexiva fundamenta-se nos trabalhos e abordagens pioneiras de Hortênsia de Hollanda, conforme discutido anteriormente, nas proposições de Schall $(1996 ; 2005)$ e na perspectiva pedagógica para ES de Mohr (2002).

Schall (1996) defendeu a necessidade de estratégias educativas para a ES que priorizem os aspectos cognitivos, considerando fundamental integrar os aspectos afetivos nos processos de ensino e aprendizagem. Para esta autora, é fundamental que a ES realizada na escola mobilize reflexões a fim de desenvolver responsabilidades com a saúde e com o ambiente: "estas devem ser as metas fundamentais da educação em saúde em uma escola comprometida com a constituição da identidade e da cidadania de seus alunos" (p. 329). A autora considera imprescindível gerar um diálogo entre cotidiano e prática, proporcionando reflexão sobre a saúde e sobre a vida dos alunos, em um contexto que proporcione a troca de experiências com os colegas e com o professor. Esta proposta avança no sentido de que a ES deve evidenciar as situações de escolha, reflexão e decisão. Neste sentido, cabe ao EC e a ES proporcionar estratégias didáticas que permitam aos alunos construir conceitos científicos e que busquem o desenvolvimento de uma atitude reflexiva e responsável pelas decisões tomadas ao longo de suas vidas (Schall, 2005).

Já os estudos de Mohr (2002) defendem que a ES na escola deve proporcionar aos sujeitos a construção de conhecimentos e práticas que lhes permitam poder e saber escolher - de maneira responsável, livre e esclarecida - suas atitudes e comportamentos. A autora afirma que a função da ES realizada na escola é incentivar e permitir ao indivíduo reflexão autônoma, para posterior ação, se assim julgar necessário. Para a pesquisadora, o comportamento relativo à saúde, depende de inúmeros componentes e condicionantes: o aspecto cognitivo resultante do ensino e da aprendizagem escolar, nem sempre é o determinante de suas ações, mas precisa estar disponível e operante para o caso de o indivíduo resolver utilizá-lo.

Amparados nestas discussões, reiteramos a importância da ES reflexiva na escola, cujo papel deve ser o de possibilitar ao aluno construir conhecimentos científicos, de forma que lhe permitam refletir, compreender a ciência, relacionar seu contexto e decidir com autonomia sobre suas ações. Estes são objetivos sintonizados com aqueles da Alfabetização Científica e Tecnológica de Fourez et al. (1997). 
Para lograr esta alfabetização, uma possibilidade é utilizar-se de abordagens reflexivas que busquem fundamentos na didática das ciências, em estudos pedagógicos e construtivistas, afastando a ES de modelos normativos e aproximando-a de aspectos oriundos da pesquisa em EC (Venturi, 2018). Outra opção poderia ser aproximar a ES da abordagem socioecológica da saúde, defendida por Carvalho (2012) e Martins et al. (2016), na qual estão presentes discussões acerca da democratização do acesso à saúde, dos direitos individuais e coletivos e da integração da saúde com aspectos socioambientais. Nesta perspectiva o cidadão compreende-se como parte da promoção da saúde, que possui dimensões e responsabilidades coletivas e individuais (Martins et al., 2015). Ali, são levados em conta ainda aspectos psicológicos, biológicos, científicos, educacionais, culturais, ocupacionais, de risco e políticos (Carvalho, 2012; Martins et al., 2016).

Compreendemos a ES como uma prática social e educacional contínua, interna e externa à escola. Contudo, ressaltamos que não é papel da escola ser reprodutora de programas e ações de saúde prescritivos e normativos, tampouco ela deve tornar-se espaço de assistência à saúde. ES na escola precisa ser reconhecida como um importante processo dinâmico e dinamizador do meio escolar, fundamental para o desenvolvimento humano (Mohr, 2002).

Os apontamentos e análises realizados neste texto, nos permitem compreender como as legislações educacionais e documentos curriculares sempre estiveram vinculados à compreensão de saúde associada à informações acerca do funcionamento do corpo humano, à prescrição de comportamentos considerados adequados para prevenção de doenças, riscos e agravos à saúde. Observamos que tentativas de ampliar essa compreensão para aquela de construção de conhecimentos para autonomia, para a formação cidadã, e que envolvesse discussões científicas e sociais acerca das condições de vida, sempre perderam espaço para compreensões de saúde como oposição à doença e ao agravo. Assim como Sousa, Guimarães e Amantes (2019), concordamos que as diretrizes educacionais sempre trataram a saúde de forma limitada, resultando em uma ES que se aproxima de uma compreensão biomédica, tecnicista, normativa e comportamentalista.

Compreender este panorama e propor outras iniciativas nos parece imperativo para que a ES possa superar velhos paradigmas em busca de novas concepções, práticas e metodologias, nas quais a prioridade e os objetivos sejam a construção de conhecimentos científicos e o desenvolvimento da autonomia para a tomada de decisões.

Os agudos problemas sanitários e sociais relacionados à desinformação do momento presente nos mostram a importância da ES e da Educação em Ciências na escola. Ambas precisam ser compreendidas como instrumentos de empoderamento individual e coletivo, por meio da compreensão de mundo, da ciência, de conhecimentos científicos, das condições sociais e de suas complexas relações com a saúde e com o comportamento humano. Seria fundamental que neste momento de avanço de perspectivas políticas e sociais ultraconservadoras e negacionistas da ciência, a ES assumisse um papel relevante no EC, com uma perspectiva reflexiva, pedagógica, com destaque para a alfabetização científica e para a formação cidadã. 
Neste sentido, desejamos que o panorama aqui apresentado possa contribuir para repensar o papel da ES na escola por meio da identificação de suas origens, influências e perspectivas no contexto escolar, e que ele favoreça reflexões epistemológicas, axiológicas e metodológicas que permitam "a compreensão da construção da ES no espaço escolar ao longo do tempo e a forte ligação existente entre o EC e a ES desenvolvida na escola" (Venturi, 2018, p. 71). Esta visão sobre a epistemologia do campo de estudos e práticas e o desenvolvimento temporal da ES, especialmente àquela realizada no contexto escolar, é imprescindível para refletir sobre pesquisas acadêmicas, práticas escolares e sobre a formação de professores.

\section{REFERÊNCIAS}

Antunes, M. J. M., Shigueno, L. Y. O., \& Meneghin, P. (1999). Métodos pedagógicos que influenciaram o planejamento das ações educativas dos enfermeiros: revisão bibliográfica. Revista Escola de Enfermagem da USP, v.33(2), p.165-74.

Bagnato, M. H. S. (1990). O ensino da saúde nas escolas de $1^{\circ}$ grau. Proposições, v.1, p.53-59.

Canguilhem, G. (2011). O normal e o patológico. $7^{\text {a }}$ Ed. Rio de Janeiro: Forense Universitária.

Carvalho, G.S (2012). Health Education in Portuguese Schools: the contribution of health and education sectors. In: Taylor, N.; Littledyke, M.; Quinn, F.; Coll, R.K. (eds). Health education in context: an international perspective on health education in schools and local communities. Rotterdam: Sense Publishers. Pp.37-46.

Cássio, F. L. (2018). Base Nacional Comum Curricular: ponto de saturação e retrocesso na educação. Retratos da Escola, v.12(23) p.239-253.

Conselho Federal de Educação (1974). Parecer 2.264/74 - Ens ( $1^{\circ}$ e $2^{\circ}$ graus), aprovado em 6-agosto-1974. Documenta, n.165, p.63-81.

Constituição da República Federativa do Brasil de 1988. (1988). Brasília.

Diniz, M. C. P., Figueiredo, B. G., \& Schall, V. T. (2009). Hortênsia de Hollanda: a arte da educação em saúde para prevenção e controle de endemias no Brasil. História, Ciência, Saúde-Manguinhos, v.16(2), p.533-556.

Figueiredo, T. A. M., Machado, V. L. T., \& Abreu, M. M. S. (2010). A saúde na escola: um breve resgate histórico. Ciência \& Saúde Coletiva, v.15(2), p.397-402, 2010.

Fourez, G., Englebert-Lecompte, V., Grootaers, D., Mathy, P., \& Tilman, F. (1997). Alfabetización científica y técnica. $1^{\mathrm{a}}$ Ed. Buenos Aires: Colihue.

Freitas, E. O., \& Martins, I. (2008). Transversalidade, formação para a cidadania e promoção da saúde no livro didático de ciências. Ensino, Saúde e Ambiente, v.1(1), p.12-28.

Gazzinelli, M. F., Gazzinelli, A., Reis, D. C., \& Penna, C. M. M. (2005). Educação em saúde: conhecimentos, representações sociais e experiências da doença. Cadernos de Saúde Pública, v.21(1), p.200-206.

Hansen, K. S. (2016). A formação de professores para a Educação em Saúde na escola: investigando o currículo de um curso de pedagogia (Dissertação de Mestrado). 
Programa de Pós-Graduação em Educação Científica e Tecnológica, Universidade Federal de Santa Catarina, Florianópolis.

Jucá, R. N. (2008) Educação e Saúde: contextos e concepções (Dissertação de Mestrado). Programa de Pós-Graduação em Ensino, Filosofia e História das Ciências, Universidade Federal da Bahia, Salvador, 2008.

Lei n. 5.692 de 11 de agosto de 1971. (1971). Fixa diretrizes e bases para o ensino de $1^{\circ}$ e $2^{\circ}$ graus e dá outras providências. Brasília: Presidência da República. Recuperado em 15 de 22ovembro de 2020, de https://www2.camara.leg.br/legin/fed/lei/19701979/lei-5692-11-agosto-1971-357752-publicacaooriginal-1-pl.html

Lei n. 9.394 de 20 de dezembro de 1996. (1996). Estabelece as diretrizes e bases da educação nacional. Brasília: Presidência da República. Recuperado em 15 de novembro de 2020, de http://www.planalto.gov.br/ccivil_03/leis/19394.htm

Lemônaco, A.F.S. (2004). Concepção de saúde e cotidiano escolar - O viés do saber e da prática. In: 27 ${ }^{\mathrm{a}}$ Reunião Anual Da Anped - GT 06 - Educação popular, 2004, Caxambu, MG. Anais [...]. Rio de Janeiro, RJ: ANPEd. Recuperado em 15 de 22ovembro de 2020, de https://anped.org.br/sites/default/files/t063.pdf

Levy, S. N., Silva, J. J. C., Cardoso, I. F. R., Werberich, P. M., Moreira, L. L. S., Montiani, H. \& Carneiro, R. M. (1997). Educação em Saúde: histórico, conceitos e propostas. Brasília: Ministério da Saúde, 29p. Recuperado em 15 de 22ovembro de 2020 de

http://www.reprolatina.institucional.ws/site/respositorio/materiais_apoio/textos_de_ap oio/Educacao_em_saude.pdf

Lima, A. L. G. S., \& Pinto, M. M. S. (2003). Fontes para a história dos 50 anos do Ministério da Saúde. História, Ciência e Saúde-Manguinhos, v.10(3), p.1037-51.

Martins, L. (2017). Abordagens da saúde em livros didáticos de biologia: análise crítica e proposta de mudança (Tese de Doutorado). Programa de Pós-Graduação em Ensino, Filosofia e História das Ciências, Universidade Federal da Bahia, Salvador.

Martins, L., Dionor, G. A., Carvalho, G. S., \& El-Hani, C. N. (2016). Abordagens de saúde nos livros didáticos de Biologia: análise das coleções aprovadas no PNLD/2012. Revista da Sbenbio, v.9, p.3050-3061.

Martins, L., Dionor, G. A., El-Hani, C. N., \& Carvalho, G. S. (2015). Construtos teóricos e práticos da saúde: as abordagens biomédicas e socioecológica. Anais do $X$ Encontro Nacional de Pesquisa em Educação em Ciências (ENPEC), Águas de Lindóia, SP.

MEC (1997). Parâmetros Curriculares Nacionais: meio ambiente e saúde. Brasília: Secretaria de Educação Fundamental.

MEC (1998 ). Diretrizes Curriculares Nacionais para o Ensino Fundamental. 1998. Parecer CEB 04/98. Brasília: Conselho Nacional de Educação. Recuperado em 15 de 22ovembro de 2020, de http://portal.mec.gov.br/cne/arquivos/pdf/PCB0498.pdf

MEC (1998b). Parâmetros Curriculares Nacionais: terceiros e quartos ciclos. Brasília: Secretaria de Educação Fundamental.

MEC (2006). Orientações curriculares para o ensino médio: Ciências da Natureza, Matemática e suas Tecnologias. Brasília: Secretaria de Educação Básica. 
MEC (2013). Diretrizes Curriculares Nacionais para Educação Básica. Brasília: Secretaria de Educação Básica.

MEC (2017). Base Nacional Comum Curricular. Brasília: Secretaria da Educação Básica.

MEC (2018). Base Nacional Comum Curricular. Brasília: Ministério da Educação. Recuperado em 15 de 23ovembro de 2020, de http://basenacionalcomum.mec.gov.br/images/BNCC_EI_EF_110518_versaofinal_sit e.pdf.

Meneghetti, F. K. (2011). O que é um ensaio-teórico? Revista de Administração Contemporânea, v.15(2), p.320-332.

Mohr, A. (2002). A natureza da educação em saúde no ensino fundamental e os professores de ciências (Tese de Doutorado). Programa de Pós-graduação em Educação, Universidade Federal de Santa Catarina, Florianópolis, SC.

Mohr, A. (2009). Ensino de Ciências e Biologia e Educação em Saúde: Análise das Proposições dos Parâmetros Curriculares Nacionais (Ensino Fundamental). In Jofili, Z. \& Almeida, A. Ensino de Biologia, Meio Ambiente e Cidadania: Olhares que se Cruzam. Recife: Ed. Univers, UFRPE.

Mohr, A. \& Schall, V. T (1992). Rumos da educação em saúde no Brasil e sua relação com a educação ambiental. Cad. Saúde Pública, Rio de Janeiro, 8 (2), p. 199-203.

Monteiro, P. H. N., \& Bizzo, N. (2015). A saúde na escola: análise dos documentos e referência nos quarenta anos de obrigatoriedade dos programas de saúde, 1971-2011. História, Ciências, Saúde-Manguinhos, v.22(2), p.411- 427.

OMS, Organização Muncial da Saúde (2002). Declaração de Sundsvall - 1991. In: As Cartas da Promoção da Saúde. Brasília: Ministério da Saúde. Recuperado em 15 de 23ovembro de 2020, de https://bvsms.saude.gov.br/bvs/23ovembro23es/cartas_promocao.pdf

OMS, Organização Muncial da Saúde. (1946). Constituição da Organização Mundial de Saúde (OMS/WHO) - 1946. Recuperado em 15 de 23ovembro de 2020, de http://www.direitoshumanos.usp.br/index.php/OMS-Organiza\%C3\%A7\%C3\%A3o-

Mundial-da-Um\%C3\%Bade/23ovembro23es23-da-organizacao-mundial-da-saudeomswho.html

OMS, Organização Muncial da Saúde. (1986). Carta de Ottawa, 1986. Recuperado em 15 de 23ovembro $\quad$ de 2020 de http://bvsms.saude.gov.br/bvs/23ovembro23es/carta_ottawa.pdf

OMS, Organização Muncial da Saúde. (2009). Nairobi Outcome document of the Highlevel United Nations Conference on South-South Cooperation, 2009. Recuperado em 15 de 23ovembro de 2020, de https://digitallibrary.un.org/record/673444

OMS, Organização Muncial da Saúde. (2020a). Coronavirus disease 2019 (COVID-19) Situation Report - 51 de 11.03.2020. Recuperado em 15 de 23ovembro de 2020 de https://www.who.int/docs/default-source/coronaviruse/situation-reports/20200311sitrep-51-covid-19.pdf?sfvrsn=1ba62e57_10

OMS, Organização Muncial da Saúde. (2020b). Entenda a infodemia e a desinformação na luta contra a Covid-19. Recuperado em 15 de 23ovembro de 2020, de 
https://iris.paho.org/bitstream/handle/10665.2/52054/Factsheet-

Infodemic_por.pdf?sequence $=14$

Renovato, R. D., \& Bagnato, M. H. S. (2010). O serviço especial de saúde pública e suas ações de educação sanitária nas escolas primárias (1942-1960). Educar em Revista, n. especial 2, p. 277-290.

Rocha, H. H. P. (2003). Educação escolar e higienização da infância. Cadernos Cedes, v.23(59), p.39-53.

Santos, R. A. (2011). O Plano de Educação Higiênica de Belisário Penna. 1900-1930. Dynamis, v.32(1), p.45-68.

Schall, V. T. (1996). Saúde e Afetividade na Infância: o que as crianças revelam e a sua importância na escola. Tese de Doutorado. Programa de Pós-Graduação em Educação, Pontifícia Universidade Católica do Rio de Janeiro, Rio de Janeiro.

Schall, V. T. (1999). Alfabetizando o corpo: o pioneirismo de Hortênsia de Hollanda na educação em saúde. Cadernos de Saúde Pública, v.15(supl.2), p.149-160.

Schall, V. T. (2005). Educação em saúde no contexto brasileiro - Influência sóciohistóricas e tendências atuais. Educação em Foco, v.1(1), p.41-58.

Schall, V. T., \& Struchiner, M. (1999). Educação em Saúde: novas perspectivas. Cadernos de Saúde Pública, v.15(supl.2), p.4-6.

Severino, A. J. (2000). Metodologia do Trabalho Científico. 21 ed. São Paulo: Cortez.

Silva, C. M. C., Meneghim, M. C., Pereira, A. C., Mialhe, F. L. (2010). Educação em Saúde: uma reflexão histórica de suas práticas. Ciências \& Saúde Coletiva, v.15(5), p.2539-2550, 2010.

Sousa, M. C., Guimarães, A. P. M., \& Amantes, A. (2019). A saúde nos documentos curriculares oficiais para o ensino de ciências: da lei de diretrizes e bases da educação à base nacional comum curricular. Revista Brasileira de Pesquisa em Educação em Ciências, v.19, p. 129-153.

Venturi, T. (2013). Educação em Saúde na escola: investigando relações entre professores e profissionais da saúde (Dissertação de Mestrado). Programa de Pósgraduação em Educação Científica e Tecnológica, Universidade Federal de Santa Catarina, Florianópolis, SC.

Venturi, T. (2018). Educação em Saúde sob uma Perspectiva Pedagógica e Formação de Professores: contribuições das Ilhotas Interdisciplinares de Racionalidade para o desenvolvimento profissional docente (Tese de Doutorado). Programa de Pósgraduação em Educação Científica e Tecnológica, Universidade Federal de Santa Catarina, Florianópolis, SC.

Venturi, T. \& Mohr, A. (2015). Contribuições do conceito de Perfil Conceitual para o campo da Educação em Saúde. Atas do X Encontro Nacional de Pesquisa em Educação em Ciências (ENPEC), Águas de Lindóia, SP.

Wendhausen, A., \& Saupe, R. (2003). Concepções de Educação em Saúde e a Estratégia de Saúde da Família. Texto e Contexto Enfermagem, v.12(1), p.17-25. 


\section{Tiago Venturi}

Doutor em Educação Científica e Tecnológica

Professor do Magistério Superior na Universidade Federal do Paraná (UFPR)

Departamento de Educação, Ensino e Ciências, Palotina, PR, Brasil.

E-mail: tiago.venturi@ufpr.br

\section{Adriana Mohr}

Doutora em Educação

Professora Titular da Universidade Federal de Santa Catarina (UFSC)

Departamento de Metodologia de Ensino, Florianópolis, SC, Brasil.

E-mail: amohr.ufsc@gmail.com

\section{Contato}

Universidade Federal do Paraná - UFPR Setor Palotina Rua Pioneiro, 2153, Bloco III, sala 4 - Dallas, Palotina/PR - CEP 85950-000

\section{Editor Responsável:}

Alessanda Bizerra

Centro de Ensino de Ciências e Matemática de Minas Gerais - CECIMIG Faculdade de Educação - Universidade Federal de Minas Gerais revistaepec@gmail.com 